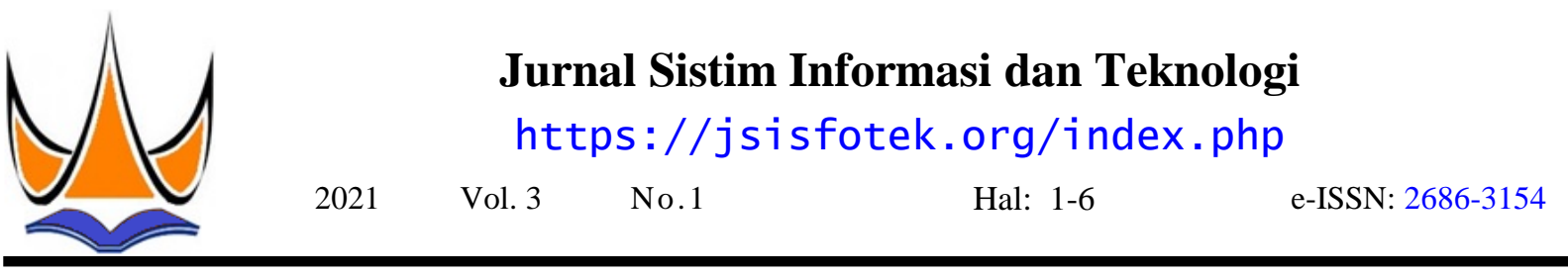

\title{
Meningkatkan Keamanan Webserver Aplikasi Pelaporan Pajak Daerah Menggunakan Metode Penetration Testing Execution Standar
}

\author{
Yosua Ade Pohan $^{1}$, Yuhandri Yunus², Sumijan ${ }^{3}$ \\ ${ }^{1,2,3}$ Universitas Putra Indonesia YPTK Padang \\ joeadepohan@gmai1.com
}

\begin{abstract}
Regional Tax Reporting Application Webserver is one of the public services for taxpayers to report their sales transactions. This application can be accessed on the domain http://sptpd.payakumbuhkota.go.id. This application is public, so the principles of information security must be applied to prevent cyber attacks. The principles of information security include confidentiality, integrity, and availability. To apply this information security principle, it is necessary to conduct vulnerability assesment of the application webserver. This study aims to improve the security of the application webserver so that the data and information in it is secure. The method used in this study is the Penetration Testing Execution Standard which is one of the methods developed by the Pentest Organization to become a standard in analyzing or auditing security systems. The results of vulnerability testing using software Acunetix, Nikto, BurpSuite and Owasp, there are seven types of vulnerabilities, namely: X-Frame Header Options is Missing, CSRF Attack, Cookie Without Only Flash, DNS Vulnerability, Ddos Attack, Bruteforce Page Login and Open Port. The vulnerability can be exploited, where the level of application vulnerability is in the medium category. The recommendations for fixing vulnerabilities can be applied by the developer, so that after repairs are made, the vulnerability level of the application webserver is in the low category and there is only one type of vulnerability, namely Brute Force Page Login.
\end{abstract}

Keywords: Pentest, Webserver, Vulnerability Assesment, Security, Attack.

Abstrak

Webserver Aplikasi Pelaporan Pajak Daerah merupakan salah satu layanan publik bagi Wajib Pajak untuk melaporkan transaksi penjualannya secara online. Aplikasi ini dapat dikases pada domain http://sptpd.payakumbuhkota.go.id. Aplikasi ini bersifat publik sehingga prinsip keamanan informasi harus diterapkan agar tidak mendapat serangan cyber. Prinsip keamanan informasi itu sendiri mencakup confidentiality, integrity, dan availability. Untuk menerapkan prinsip keamanan informasi tersebut maka perlu dilakukan pengujian kerentanan terhadap webserver aplikasi. Penelitian ini bertujuan untuk meningkatkan keamanan webserver aplikasi sehingga data dan informasi didalamnya terjaga kemanannya. Metode yang digunakan pada penelitian ini adalah Penetration Testing Execution Standar yang merupakan salah satu metode yang dikembangkan Pentest Organisation untuk menjadi standar dalam menganalisa atau mengaudit sistem kemanan Hasil dari pengujian kerentanan menggunakan software Acunetix, Nikto, BurpSuite dan Owasp terdapat tujuh buah jenis kerentanan yaitu: X-Frame Header Options is Missing, CSRF Attack, Cookie Without OnlyFlag, DNS Vulnerability, Ddos Attack, Bruteforce Page Login dan Open Port. Kerentanan dapat dilakukan exploitasi, dimana level kerentanan aplikasi adalah pada kategori medium. Rekomendasi perbaikan kerentanan dapat diterapkan oleh pengembang, sehingga setelah dilakukan perbaikan maka level kerentanan webserver aplikasi pada kategori low dan hanya terdapat satu jenis kerentanan yaitu Brute Force Page Login.

Kata kunci: Pentest, Webserver, Penilaian Kerentanan, Keamanan, Serangan.

(C) 2021 JSisfotek

\section{Pendahuluan}

Badan Keuangan Daerah Kota Payakumbuh telah mengembangkan layanan publik untuk pelaporan pajak daerah secara online. Manfaat layanan publik bagi pemerintahan adalah dapat mengurangi human error dan meningkatkan efektivitas kerja, meningkatkan dalam pengambilan keputusan serta memudahkan masyarakat tanpa harus mendatangi kantor [1]. Berdasarkan data Badan Siber dan Sandi Negara Tahun Webserver aplikasi pajak daerah menggunakan Bahasa 2019, situs milik Pemerintah cukup banyak terjadi Pemrograman PHP, dimana Engine PHP serangan seperti: Web Defacement 34\%, Phising 9\%, menerjemahkan PHP ke webserver yang ada, apa yang Malware 13\%, Kerentanan lain 37\% [2]. Berdasarkan sebenarnya dilihat oleh pengguna di browser adalah data tersebut maka aplikasi layanan publik harus bukan file PHP itu sendiri melainkan output dari semua diterapkan prinsip dari keamanan informasi. Prinsip perintah PHP yang dikrimkan kembali oleh webserver kemanan informasi terdiri dari Confidentiality yaitu [4]. Berdasarkan data dan informasi tersebut maka Diterima: 07-10-2020 | Revisi: 21-10-2020 | Diterbitkan: 31-03-2021 | DOI: 10.37034/jsisfotek.v3i1.36 kerahasiaan, Integrity yaitu data tidak berubah dari aslinya dan Availability yaitu ketersediaan [3]. Webserver aplikasi pelaporan pajak daerah dapat diakses di domain http://sptpd.payakumbuhkota.go.id. Aplikasi ini dapat diakses oleh publik sehingga terbuka untuk dilakukan serangan, data dan informasi didalamnya juga bersifat sensitive karena berhubungan dengan transaksi keuangan wajib pajak. 
webserver aplikasi perlu dilakukan pengujian Tahap ini dilakukan interaksi dengan Badan Keuangan kerentanan untuk mencari celah keamanan dan Daerah, mengenai tujuan dari penelitian, menentukan dilakukan perbaikannya. Penilaian kerentanan bisa scope dan pertanyaan mengenai gambaran umum mendeteksi hampir semua celah kerentanan yang webserver aplikasi.

biasanya terjadi pada sebuah sistem [5]. Metode yang digunakan adalah Penetration Testing Execution

Standar yang dikembangkan Pentest Organisation Tahap ini peneliti mengumpulkan informasi mengenai untuk menjadi standar dalam menganalisa atau webserver aplikasi, cara kerja sistem, IP Address dan mengaudit sistem kemanan. Beberapa penelitian yang lainnya.

dilakukan dengan Penetration Testing diantaranya Penetration Testing dapat dilakukan pada Internet of c. Threat Modelling

thing didapatkan hasil kerentanan dari tiga lapisan layer Tahapan ini peneliti menggunakan informasi yang yaitu application layer, network layer dan perception didapat untuk membuat gambaran model ancaman apa layer, terdapat kelemahan password yang tidak yang dapat terjadi pada aplikasi. Menentukan aset kritis dienkripsi, kerentanan sniffing dan spoofing [6]. dan dampak yang terjadi.

Penelitian berikutnya dilakukan dengan melakukan pengujian keamanan terhadap 3 buah aplikasi web d. Vulnerability Analysis

dengan metode Penetration Testing. Hasil pengujian Tahapan ini dilakukan pemindaian kerentanan dan didapatkan kelamahan berupa missing X-XSS header analisis hasil kerentanan dan menentukan jenis protection, insecure transportation security protocol serangan apa yang bisa dilakukan exploitasi.

(TLS 1.0), sourcode disclousure dan beberapa file jquery yang sudah kadaluarsa [7].

Pengujian kerentanan juga dapat dilakukan pada website paud dikmas dengan menggunakan metode Penetration Testing, terdapat celah keamanan seperti Port FTP yang terbuka, web application information disclosure, dan lemahnya keamanan untuk autentikasi login pada website [8]. Penetration Testing juga dapat dilakukan terhadap IP server 192.168.197.130. Hasil pengujian terdapat beberapa kelemahan yaitu terbukanya port FTP dan SSH yang bisa dilakukan exploitasi kedalamnya [9]. Penetration Testing juga dapat dilakukan pada localhost dengan hasil kerentanan X-Frame Option Header Missing, Cross site scripting (XSS) dan SQL Injection [10]. Penelitian lainnya adalah dengan penetrasi aplikasi web didapat hasil $S Q L$ Injection, Cross Site Scripting, Local File Inclusion (LFI) dan Parameter Tampering [11]. Untuk Kerangka kerja dibutuhkan agar peneliti memiliki meningkatkan keamanan webserver aplikasi pelaporan pedoman dan arah yang jelas dalam melakukan

pajak daerah agar sesuai dengan prinsip keamanan penelitian [13].

informasi maka perlu dilakukan pengujian kerentanan aplikasi dengan menggunakan Metode Penetration Testing Execution Standar.

\section{Metodologi Penelitian}

\subsection{Subjek Penelitian}

Subjek pada penelitian ini adalah pada webserver aplikasi pelaporan pajak daerah, dengan domain http://sptpd.payakumbuhkota.go.id. Penelitian dilakukan dengan melakukan pengujian terhadap aplikasi (source code) dan webserver sebagai tempat berjalanya aplikasi.

\subsection{Metode Penetration Testing Execution Standar}

Tahapan dalam metode Penetration Testing Execution Standar adalah [12]:

a. Pre-Engegment

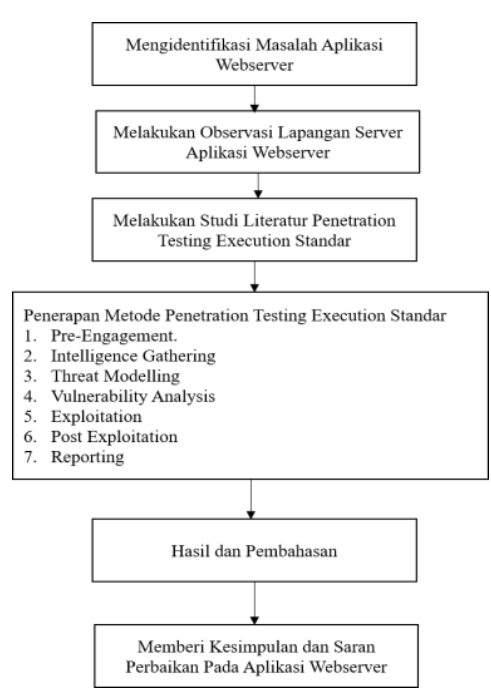

Tahap ini dilakukan serangan terhadap kerentanan yang ditemukan sekaligus menguji apakah kerentanan tersebut memang benar bisa di exploitasi.

\section{f. Post Exploitation}

Tahap ini dilakukan perbaikan dengan menerapkan solusi yang tepat untuk mengatasi kerentanan dan dilakukan kembali pengujian kerentanan.

\section{g. Reporting}

Tahap ini peneliti membuat laporan berupa hasil pengujian kerentanan sebelum dilakukan perbaikan bug dan setelah dilakukan perbaikan bug.

\subsection{Kerangka Kerja Penelitian}


Kerangka kerja penelitian tiap tahapnya memiliki Hasil pemindaian port dengan menggunakan tool nmap keterkaitan dengan tahap berikutnya [14]. Penelitian didapat hasil:

dimulai dengan mengidentifikasi masalah pada webserver aplikasi, melakukan observasi langsung webserver aplikasi, melakukan studi literatur mengenai penetrasi testing, menerapkan metode yang digunakan, melakukan hasil dan pembahasan serta membuat kesimpulan dan saran [15].

\section{Hasil dan Pembahasan}

\subsection{Analisa Data}

Data yang digunakan dalam penelitian ini adalah webserver aplikasi dengan domain http://sptpd.payakumbuhkota.go.id. Data awal yang agents (penyerang) sebagai berikut:

diperoleh oleh peneliti adalah

1. Adanya serangan Brute Force SSH pada webserver.

2. Response time yang lambat dari aplikasi pada saat tertentu.

3. Adanya serangan terhadap Header HTTP berdasarkan log access yang diterima.

\subsection{Penerapan Penetration Testing Execution Standar}

\subsubsection{Pre-Engagement}

Tahap ini dilakukan interaksi dengan Badan Keuangan Daerah dan menentukan scope penelitian yaitu di domain http://sptpd.payakumbuhkota.go.id. Hasil dai tahapan ini sebagai berikut;

a. Waktu Penelitian disepakati 40 hari kerja.

b. Waktu untuk penetrasi testing dilakukan setelah jam kerja.

c. Backup aplikasi dilakukan rutin setiap hari.

d. Username dan Password aplikasi dan webserver dapat diberikan jika diperlukan.

\subsubsection{Intelligence Gathering}

Tahap ini peneliti mulai melakukan pencarian informasi terkait webserver aplikasi sebagai berikut:

a. IP Whois

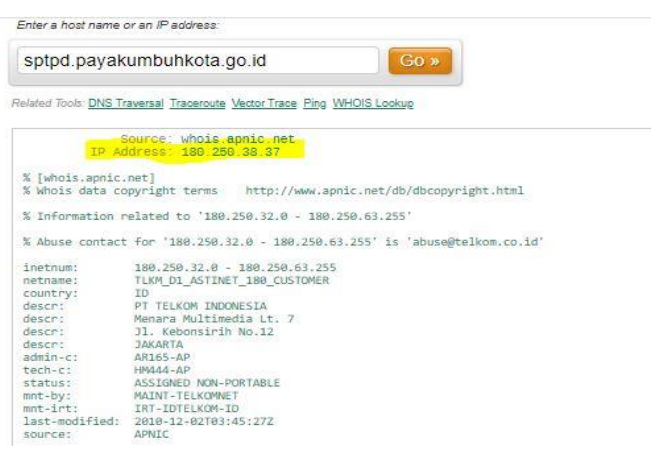

Gambar 2. Ip Whois

Tabel 1. Hasil Pemindaian Port dengan Nmap

\begin{tabular}{lrll}
\hline No & Port & Status & Service \\
\hline 1 & 21 & Open & File Transfer Protocol $($ FTP $)$ \\
2 & 25 & Open & SMTP (Email) \\
3 & 53 & Open & DNS Server \\
4 & 80 & Open & Httpd (Apache) \\
5 & 3306 & Open & MySQL \\
6 & 10000 & Open & Webmin Panel \\
\hline
\end{tabular}

\subsubsection{Threat Modelling}

Peneliti pada tahap ini membuat gambaran model ancaman yang terjadi aplikasi berdasarkan dari threat

Tabel 2. Threat Agents berdasarkan motivation

\begin{tabular}{lll}
\hline No & Motivasi & Possibility \\
\hline 1 & Balas Dendam & High \\
2 & Keingintahuan & High \\
3 & Financial & High \\
4 & Politik & Medium \\
5 & Terorisme & Low \\
6 & Agama & Low \\
\hline
\end{tabular}

Tabel 3. Threat Agents berdasarkan Capability

\begin{tabular}{|c|c|c|}
\hline No & Capability & Analisa terhadap Aplikasi \\
\hline 1 & $\begin{array}{l}\text { Tool yang } \\
\text { digunakan }\end{array}$ & $\begin{array}{l}\text { Scanning Tools (Acunetix, } \\
\text { Nmap) } \\
\text { Exploitation tool: KaliLinux }\end{array}$ \\
\hline 2 & $\begin{array}{l}\text { Ketersediaan } \\
\text { Payload/exploits }\end{array}$ & $\begin{array}{l}\text { Mudah dan cukup banyak } \\
\text { tersedia untuk membuat serangan } \\
\text { ke aplikasi }\end{array}$ \\
\hline 3 & $\begin{array}{l}\text { Mekanisme } \\
\text { Komunikasi }\end{array}$ & $\begin{array}{l}\text { Adanya diskusi, lokakarya, } \\
\text { seminar antara threat agents } \\
\text { membuat serangan terhadap } \\
\text { aplikasi meningkat, }\end{array}$ \\
\hline 4 & Aksesibiltas & $\begin{array}{l}\text { Ketersediaan internet, tool dan } \\
\text { modul untuk serangan dapat } \\
\text { meningkatkan ancaman terhadap } \\
\text { webserver. }\end{array}$ \\
\hline
\end{tabular}

\subsubsection{Vulnerability Analysis}

Tahapan ini dilakukan untuk mencari kelemahan dengan melakukan pemindaian aplikasi dengan menggunakan tool Acunetix yang berfungsi untuk melakukan pengujian keamanan Web didapat hasil kerentanan sebagai berikut:

Tabel 4. Hasil Kerentanan Webserver Aplikasi

\begin{tabular}{|c|c|c|c|}
\hline No & Indikasi File & Jenis Kerentanan & Kategori \\
\hline 1 & $/ \operatorname{login} . \mathrm{php}$ & $\begin{array}{l}\text { X-Frame Header Options } \\
\text { is Missing }\end{array}$ & Medium \\
\hline 2 & /login.php & $\begin{array}{l}\text { HTML Form without CSRF } \\
\text { Protection }\end{array}$ & Medium \\
\hline 3 & I & $\begin{array}{l}\text { Cookie without HttpOnly } \\
\text { flag set }\end{array}$ & Medium \\
\hline 4 & /login.php & $\begin{array}{l}\text { Login page-password- } \\
\text { guessing attack }\end{array}$ & Low \\
\hline 5 & $\begin{array}{l}\text { Port 21, 25, 53, } \\
10000\end{array}$ & Open Port & Low \\
\hline 6 & $\begin{array}{l}\text { Bind DNS } \\
\text { Server }\end{array}$ & DNS Vulnerability & Low \\
\hline 7 & Httpd (Apache) & Ddos Vulnerability & Low \\
\hline
\end{tabular}

Berdasarkan Gambar 2 IP Publik webserver aplikasi yang digunakan adalah 180.250.38.37 Astinet Telkom.

Berdasarkan hasil analisa kerentanan maka didapat 7 jenis kerentanan yang dapat dilakukan exploitasi 
terhadap webserver aplikasi yang dijelaskan sebagai Tahapan ini peneliti melakukan pengujian terhadap berikut:

\section{a. Clickjacking}

Deskripsi: Kerentanan disebabkan Header Options tidak di konfigurasi SAMEORIGIN.

Dampak: Frame bisa di load dari URL selain URL Aplikasi sehingga korban bisa melakukan click pada aplikasi dimana informasi sensitive bisa dikirim ke penyerang.

\section{b. Cross Site Request Forgery Attack}

Deskripsi: Kerentanan disebabkan tidak menyertakan token dalam validasi data POST.

Dampak: Penyerang bisa melakukan update data pada aplikasi dengan memanfaatkan ketidaktahuan dari user. Penyerang memaksa user untuk melakukan aksi yang tidak diinginkan oleh user.

\section{c. Session Hijacking}

Deskripsi: Kerentanan disebabkan cookies saat user login tidak dikonfigurasi ke secure atau HttpOnly.

Dampak: Penyerang dapat melakukan sniffing dan mendapatkan cookies user, yang akan digunakan oleh peneyerang untuk baypass login aplikasi secara illegal, sehingga data bisa dimodifikasi.

\section{d. Brute Force Attack}

Deskripsi: Kerentanan disebabkan page index aplikasi adalah halaman login sehingga terbuka dan aplikasi tidak berjalan pada port https.

Dampak: Penyerang dapat masuk kedalam aplikasi dengan melakukan percobaan menebak kata sandi untuk login aplikasi sehingga data dapat dimodifikasi.

\section{e. Open Port Attack}

Deskripsi: Kerentanan disebabkan tidak ada filter terhadap port yang perlu dibuka dan ditutup.

Dampak: Penyerang dapat mengupload file backdoor pada aplikasi dan menghentikan service yang diberikan oleh port tersebut.

\section{f. DNS Attack}

Deskripsi: Kerentanan disebabkan DNS tidak diinstall DNSSEC dan mode recursion yes

Dampak: Penyerang dapat melakukan DNS Spoofing dan DNS Amplification.

\section{g. Ddos Attack}

Deskripsi: Kerentanan disebabkan tidak ada instalasi mod_security untuk melakukan filtering terhadap paket yang masuk.

Dampak: Traffic dari webserver aplikasi menjadi besar sehingga kehabisan resource dan membuat tidak dapat diakses.

\subsubsection{Exploitation} hasil kerentanan dengan melakukan exploitasi. Tujuan dari tahapan ini adalah untuk membuktikan apakah hasil kerentanan dapat diexploitasi berdasarkan analisa yang dilakukan sebelumnya.

a. Clickjacking

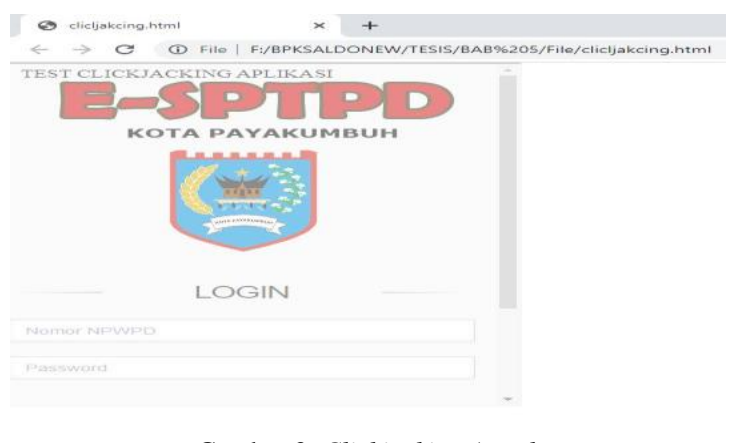

Gambar 3. Clickjacking Attack

b. CSRF Attack

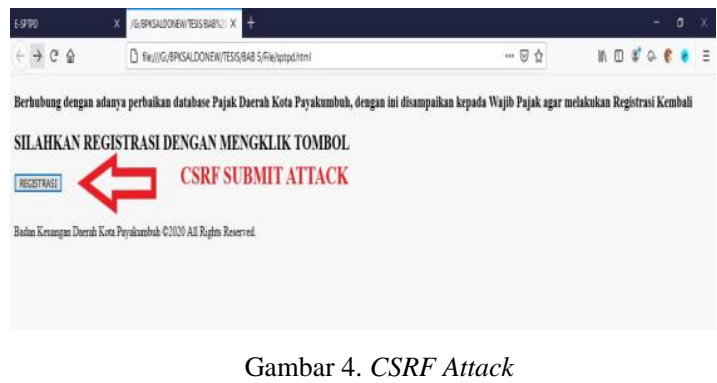

c. Session Hijacking

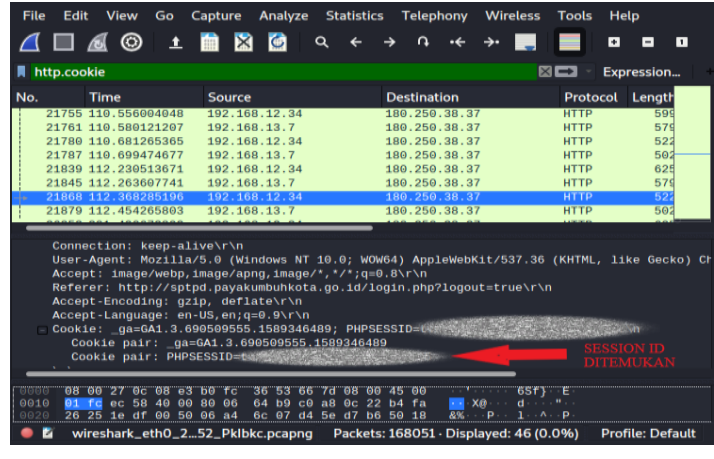

Gambar 5. Session Hijacking

d. Brute Force Attack

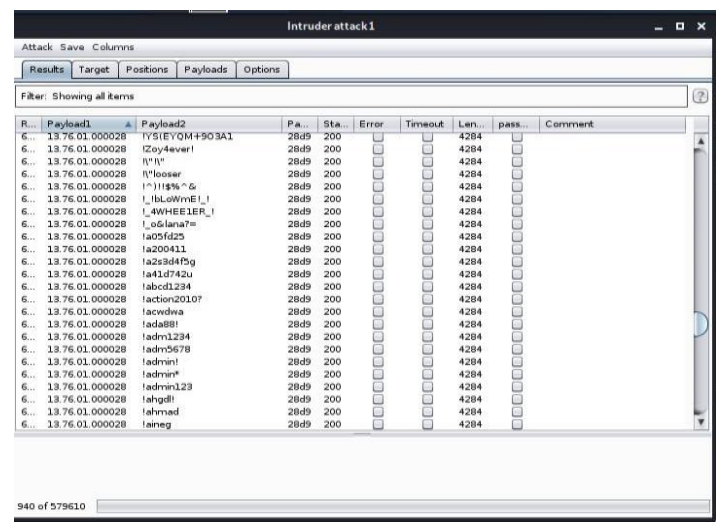

Gambar 6. Brute Force Attack

Jurnal Sistim Informasi dan Teknologi Vol.3 No. 0.1 (2021) 1-6 
e. Open Port Attack

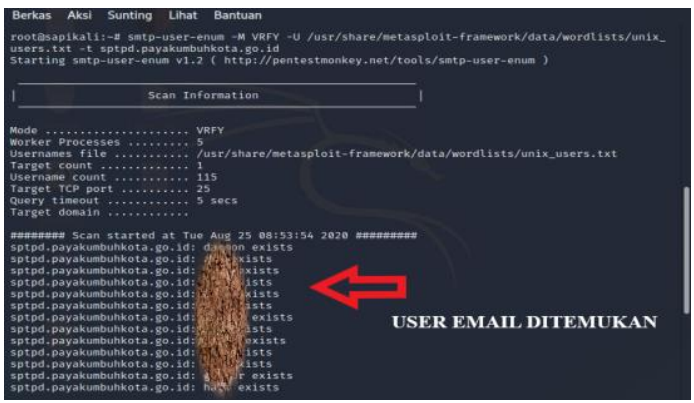

Gambar 7. Port Attack

f. DNS Attack

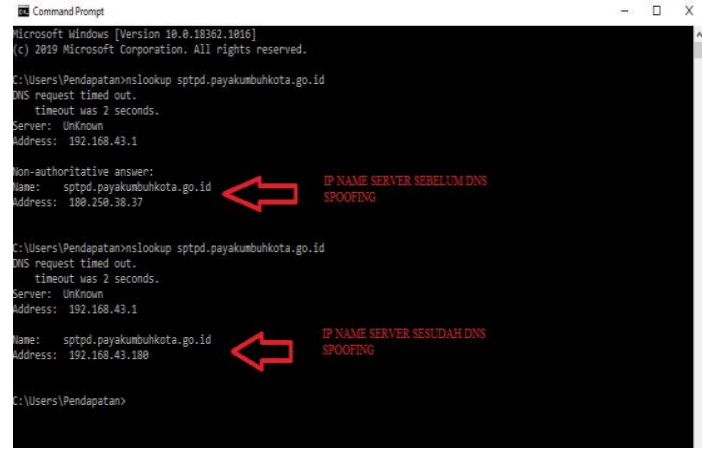

Gambar 8. DNS Spoofing

\section{g. DDos Attack}

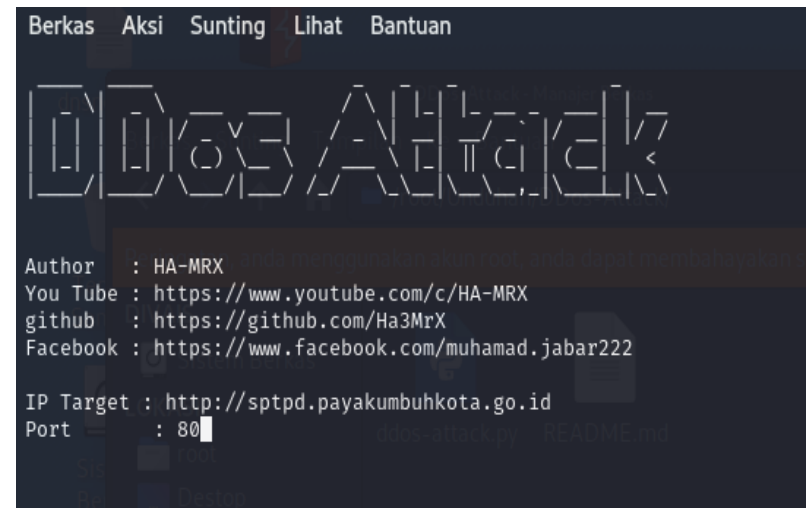

Gambar 9. DDos Attack

Berdasarkan Hasil exploitasi yang dilakukan terhadap jenis kerentanan maka disimpulkan semua jenis kerentanan pada aplikasi dapat di lakukan exploitasi.

\subsubsection{Post Exploitation}

Sesudah tahapan exploitation, maka pada tahapan ini dilakukan perbaikan berdasarkan solusi yang tepat untuk mengatasi kerentanan.
Tabel 5. Solusi Terhadap Jenis Kerentanan

\begin{tabular}{|c|c|c|}
\hline No & $\begin{array}{c}\text { Jenis } \\
\text { Kerentanan }\end{array}$ & Solusi \\
\hline & & Setting Header Options ke \\
\hline & $X$-Frame & SAMEORIGIN dan DENY \\
\hline 1 & $\begin{array}{l}\text { Header Options } \\
\text { is Missing }\end{array}$ & $\begin{array}{l}\text { Menambahkan SSL pada webserver } \\
\text { aplikasi sehingga pertukaran data lebih } \\
\text { secure karena menggunakan https. }\end{array}$ \\
\hline 2 & $\begin{array}{l}\text { HTML Form } \\
\text { without CSRF } \\
\text { Protection }\end{array}$ & $\begin{array}{l}\text { Menambahkan token autentikasi pada } \\
\text { saat pengiriman data dengan POST }\end{array}$ \\
\hline 3 & $\begin{array}{l}\text { Cookie without } \\
\text { HttpOnly flag } \\
\text { set }\end{array}$ & $\begin{array}{l}\text { Melakukan konfigurasi cookies flag ke } \\
\text { Secure atau HttpOnly }\end{array}$ \\
\hline 4 & $\begin{array}{l}\text { Login page- } \\
\text { password- } \\
\text { guessing attack }\end{array}$ & $\begin{array}{l}\text { Menambahkan instalasi fail2ban pada } \\
\text { webserver dan menambahkan rule untuk } \\
\text { melakukan filter serangan bruteforce }\end{array}$ \\
\hline & & $\begin{array}{l}\text { Mengganti port default webmin. } \\
\text { Mengganti port ssh dari port } 22 \mathrm{ke} \text { port } \\
\text { lainnya }\end{array}$ \\
\hline 6 & $\begin{array}{l}\text { DNS } \\
\text { Vulnerability }\end{array}$ & $\begin{array}{l}\text { Melakukan konfigurasi Bind DNS } \\
\text { dengan mengaktifkan DNSSEC dan } \\
\text { menonaktifkan mode recursive }\end{array}$ \\
\hline 7 & $\begin{array}{l}\text { Ddos } \\
\text { Vulnerability }\end{array}$ & $\begin{array}{l}\text { Melakukan instalasi } \text { mod_security dan } \\
\text { menambahkan rule untuk melakukan } \\
\text { block serangan DDos terhadap Port TCP } \\
\text { dan UDP. }\end{array}$ \\
\hline
\end{tabular}

\subsubsection{Reporting}

Tahap terakhir dari Metode Penetration Testing Execution Standar adalah membuat laporan pengujian kerentanan. Hasil penerapan solusi terhadap jenis kerentanan aplikasi dapat meningkatkan keamanan dari yang sebelumnya berkategori Medium menjadi Kategori Low, seperti pada Gambar berikut:

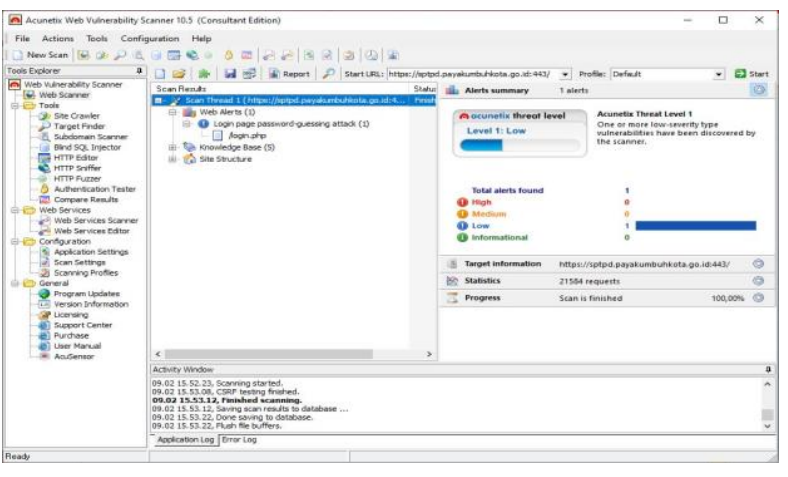

Gambar 10 Kategori Kerentanan Setelah Perbaikan 
Laporan secara rinci Hasil pengujian kerentanan dapat [2] Badan Siber Sandi Negara. (2019). Laporan Tahunan Govdisimpulkan sebagai berikut: CSIRT 2019

Tabel 6 Hasil Pengujian Kerentanan

\begin{tabular}{|c|c|c|c|}
\hline No & $\begin{array}{l}\text { Jenis } \\
\text { Kerentanan }\end{array}$ & Hasil Exploitasi & $\begin{array}{l}\text { Hasil Sesudah } \\
\text { Perbaikan }\end{array}$ \\
\hline 1 & $\begin{array}{l}\text { X-Frame } \\
\text { Header } \\
\text { Options is } \\
\text { Missing }\end{array}$ & $\begin{array}{l}\text { Dapat dilakukan } \\
\text { serangan Clickjacking }\end{array}$ & $\begin{array}{l}\text { Aplikasi } \\
\text { memblock } \\
\text { Serangan } \\
\text { Clickjacking }\end{array}$ \\
\hline 2 & $\begin{array}{l}\text { HTML Form } \\
\text { without } \\
\text { CSRF } \\
\text { Protection }\end{array}$ & $\begin{array}{l}\text { Dapat dilakukan } \\
\text { update data melalui } \\
\text { form submit CSRF } \\
\text { Attack }\end{array}$ & $\begin{array}{l}\text { Webserver } \\
\text { menolak request } \\
\text { tanpa adanya } \\
\text { token }\end{array}$ \\
\hline 3 & $\begin{array}{l}\text { Cookie } \\
\text { without } \\
\text { HttpOnly flag } \\
\text { set }\end{array}$ & $\begin{array}{l}\text { Session Cookies dari } \\
\text { user login dapat di } \\
\text { capture dengan } \\
\text { sniffing wireshark }\end{array}$ & $\begin{array}{l}\text { Session cookies } \\
\text { tidak terbaca di } \\
\text { wireshark }\end{array}$ \\
\hline 4 & $\begin{array}{l}\text { Login page- } \\
\text { password- } \\
\text { guessing } \\
\text { attack }\end{array}$ & $\begin{array}{l}\text { Penyerang dapat } \\
\text { mengirim POST data } \\
\text { username dan } \\
\text { password secara } \\
\text { berulang-ulang. }\end{array}$ & $\begin{array}{l}\text { Webserver } \\
\text { menolak POST } \\
\text { data login.php } \\
\text { dengan status } 403 \\
\text { Forbidden }\end{array}$ \\
\hline 5 & Open Port & $\begin{array}{l}\text { Port SMTP dapat } \\
\text { dieksplotasi dan } \\
\text { mendapatkan } u s e r \\
\text { email aktif }\end{array}$ & $\begin{array}{l}\text { Eksploitasi tidak } \\
\text { berhasil } \\
\text { mendapatkan user } \\
\text { email aktif }\end{array}$ \\
\hline 6 & $\begin{array}{l}\text { DNS } \\
\text { Vulnerability }\end{array}$ & $\begin{array}{l}\text { Penyerang dapat } \\
\text { melakukan } D N S \\
\text { Spoofing dan DNS } \\
\text { Amplification terhadap } \\
\text { aplikasi }\end{array}$ & $\begin{array}{l}\text { Serangan DNS } \\
\text { Spoofing dan DNS } \\
\text { Amplification } \\
\text { dapat di block } \\
\text { oleh aplikasi }\end{array}$ \\
\hline 7 & $\begin{array}{l}\text { DDos } \\
\text { Vulnerability }\end{array}$ & $\begin{array}{l}\text { Dapat dilakukan } \\
\text { exploitasi sehingga } \\
\text { aplikasi tidak dapat } \\
\text { diakses }\end{array}$ & $\begin{array}{l}\text { Aplikasi tetap } \\
\text { dapat diakses } \\
\text { dengan } \\
\text { melakukan filter } \\
\text { paket }\end{array}$ \\
\hline
\end{tabular}

\section{Kesimpulan}

Metode Penetration Testing Execution Standar dapat diterapkan pada webserver aplikasi pelaporan pajak daerah. Kategori keamanan aplikasi yang sebelumnya pada kategori Medium dengan 7 buah jenis kerentanan dapat diturunkan menjadi kategori Low dengan hanya 1 buah jenis kerentanan, sehingga keamanan webserver aplikasi pelaporan pajak daerah dapat ditingkatkan. Penelitian selanjutnya agar Metode Penetration Testing Execution Standar dapat dilakukan dalam melakukan analisa keamanan jaringan.

\section{Daftar Rujukan}

[1] Sugiartawan, P., Rustina, I. D. K. R., \& Insani, R. W. S. (2018). E-Government Media Informasi Alat Kelengkapan Dewan Provinsi Bali dan Media Diskusi Berbasis Website. Jurnal Sistem Informasi dan Komputer Terapan Indonesia (JSIKTI), 1(2), 7586. DOI: https://doi.org/10.33173/jsikti.17 .
[3] Azis, H., \& Fattah, F. (2019). Analisis Layanan Keamanan Sistem Kartu Transaksi Elektronik Menggunakan Metode Penetration Testing. Ilkom Jurnal Ilmiah, 11(2), 167-174. DOI: https://doi.org/10.33096/ilkom.v11i2.447.167-174

[4] Karayiannis, C. (2019). Web-Based Projects that Rock the Class. Build Fully-Functional Web Apps and Learn Through Doing. Apress. DOI: https://doi.org/10.1007/978-1-4842-4463-0 .

[5] Goel, J. N., Mehtre, B. M. (2015). Vulnerability Assessment \& Penetration Testing as Cyber Defence Technology. Procedia Computer Science, 57, 710-715. DOI: https://doi.org/10.1016/j.procs.2015.07.458.

[6] Chu, G., \& Lisitsa, A. (2018). Penetration Testing for Internet of Things and Its Automation. In 2018 IEEE 20th International Conference on High Performance Computing and Communications; IEEE 16th International Conference on Smart City; IEEE 4th International Conference on Data Science and Systems (HPCC/SmartCity/DSS), 1479-1484. DOI: https://doi.org/10.1109/HPCC/SmartCity/DSS.2018.00244 .

[7] Krasniqi, G., \& Bejtullahu, V. (2018). Vulnerability Assessment \& Penetration Testing: Case Study On Web Application Security. UBT Knowlegde Center - Making Local Knowlegde Visible. DOI: https://doi.org/10.33107/ubt-ic.2018.213 .

[8] Syarifudin, I. (2018). Pentesting dan Analisis Keamanan Web Paud Dikmas. Zenodo.org. DOI: https://doi.org/10.5281/zenodo.1211847.

[9] Khera, Y., Kumar, D., Sujay, S., \& Garg, N. (2019). Analysis and Impact of Vulnerability Assessment and Penetration Testing. In Proceedings of the International Conference on Machine Learning, Big Data, Cloud and Parallel Computing: Trends, Prespectives and Prospects, COMITCon, 525-530. DOI: https://doi.org/10.1109/COMITCon.2019.8862224 .

[10]Goutam, A., \& Tiwari, V. (2019). Vulnerability Assessment and Penetration Testing to Enhance the Security of Web Application. In 2019 4th International Conference on Information Systems and Computer Networks, ISCON, 601-605. DOI: https://doi.org/10.1109/ISCON47742.2019.9036175.

[11]Gupta, U., Raina, S., Verma, P., Singh, P., \& Aggarwal, M. (2020). Web Penetration Testing. International Journal for Research in Applied Science and Engineering Technology, 8(5), 56-60. DOI: https://doi.org/10.22214/ijraset.2020.5011 .

[12] Abu-Dabaseh, F., \& Alshammari, E. (2018). Automated Penetration Testing: An Overview. Academy and Industry Research Collaboration Center (AIRCC), 121-129. DOI: https://doi.org/10.5121/csit.2018.80610

[13]Ula, M. (2019). Evaluasi Kinerja Software Web Penetration Testing. TECHSI - Jurnal Teknik Informatika, 11(3). DOI: https://doi.org/10.29103/techsi.v11i3.1996 .

[14]M, S. P., \& Lobo, S. J. (2019). A Study on Advanced Cross Site Request Forgery Attacks and its Prevention. Journal of Web Development and Web Designing, 4(2), 31-35. DOI: http://doi.org/10.5281/zenodo.3346240.

[15]James, L., \& D, D. E. (2020). Technique to Thwart Brute-Force Attack: A Survey. International Journal of Scientific Research in Science, Engineering and Technology, 7(1), 235-237. DOI: https://doi.org/10.32628/ijsrset207139 . 